doi: $10.15407 /$ ujpe60.12.1263

A.G. BELIKOV, V.G. PAPKOVICH

National Science Center "Kharkiv Institute of Physics and Technology"

(1, Akademichna Str., Kharkiv 61108,Ukraine; e-mail: papkovich@kipt.kharkov.ua)

\title{
ISOTOPE SEPARATION IN THE REFLECTED ION PACS 71.20.Nr, 72.20.Pa BEAM IN A SYSTEM WITH A CUSP MAGNETIC FIELD
}

\begin{abstract}
The isotope separation in a reflected ion beam injected into a cusp magnetic field has been considered. The magnetic field configuration was formed by two rings with oppositely directed currents. The motion of the particles entering the system and reflected by the increasing magnetic field of the second ring is numerically calculated. A possibility for reflected particles to be separated in the radial direction is shown. This effect allows an annular ion source to be used, which leads to an increase in the total current and the performance of the system.

Ke ywords: isotope separation, cusp magnetic field, reflected beam.
\end{abstract}

A possibility of using a system with cusp magnetic field for the isotope separation was reported in work [1]. The magnetic field was created with the help of two coils with the currents running in opposite directions. The attention was attracted to the fact that the passage of particles through a region with a weakened magnetic field in the central part of the system, where the longitudinal component of the magnetic field vanishes and the field direction changes, has the most substantial effect on the isotope separation. In this region, the conditions of particle motion adiabaticity are violated. Therefore, the trajectories of particles with a small mass difference, which start from a position shifted with respect to the symmetry axis of the system, can differ considerably in space after their passage through the central part of the system, when the particles move further along helical trajectories in a uniform magnetic field, where particle collectors are arranged.

The experiments on the separation of ${ }^{6} \mathrm{Li}$ and ${ }^{7} \mathrm{Li}$ isotopes in a system with cusp magnetic field were successfully performed in work [2]. On the basis of the corresponding analysis, it was shown that the system

(C) A.G. BELIKOV, V.G. PAPKOVICH, 2015

ISSN 2071-0194. Ukr. J. Phys. 2015. Vol. 60, No. 12 concerned is cheaper in comparison with other methods of isotope separation.

The numerical calculations [3] allowed the capabilities and restrictions of this isotope separation method to be analyzed in more details. Particles were supposed to be injected with the help of a point-like source shifted with respect to the axis of the system. The initial conditions (source position, initial velocity of ions, the magnetic field) were selected so that the ions emitted from the source and moving along a helical trajectory should cross the plane of zero magnetic field and leave the magnetic field in the form of beams of separated isotopes. It was demonstrated that the system is capable of separating the isotopes of both light and heavy elements. A considerable separation with respect to the particle mass was achieved along the beam motion direction in parallel to the axis of the system and in the azimuthal direction in the plane perpendicular to the axis at the fixed coordinate $z$. Restrictions affecting the separation, which are associated with large transverse components of particle velocities in the flux and the source dimensions, were estimated. The size of the ion injecting area (this parameter mainly concerns the radial dimension of a source) was selected not to worsen the separation coefficient. As a result, the flux emit- 
ted by the source and, accordingly, the performance of the system were confined.

In order to enhance the efficiency, a system with two reverses of the magnetic field was considered in work [4]. The magnetic system was supplemented with another coil. It was shown that, after the passage of two planes with the zero magnetic field, particles with close masses become separated along the radial coordinate. This geometry makes it possible to apply an annular ion source in the two-reverse system and, in such a way, to increase the total current and, accordingly, the installation efficiency.

In all cases considered above, the mass separation was carried out for transmitting particles, i.e. particles starting from the left boundary of the system and arriving at the system output. In work [5], it was shown that if particles are injected from an end face into a system with cusp fields, some types of trajectories can be distinguished.

In this work, we consider the motion of particles that do not pass through the whole system, but, after crossing the plane of zero magnetic field, are reflected by an increasing field of the second coil. After their reflection, those particles can make some oscillations and either leave the system through an annular gap at the center or return to the start position. Some reasons for the choice of particles with these kinds of trajectories can be explained as follows.

If a particle with mass $M_{1}$ and velocity $v$ flies from the region $z<0$, where the magnetic field equals zero, into the half-space $z>0$ with a uniform transverse magnetic field $H=H_{0}$, it penetrates to a depth equal to the Larmor radius, $r_{l 1}$. Having described a half-circular trajectory, the particle leaves the magnetic field region, being radially shifted with respect to its initial path. A particle with a different mass $M_{2}$, which starts to move as the first particle, penetrates to the depth $r_{l 2}$ and leaves the magnetic field region with the radial shift $2 r_{l 2}$. As a result, those two particles, after they left the magnetic field, move along the trajectories shifted by $2 \Delta r$ with respect to each other, where $\Delta r=r_{l 2}-r_{l 1}$. If the magnetic field is not changed in a jump-like manner, but linearly grows from zero to $H_{0}$ within a certain interval $L$, the particle penetration depth into the magnetic field is determined by the formula $d=r_{l} \sqrt{2 L / r_{l}}$ [6] depending on the length $L$. So, the difference between the trajectories of the same particles, when they left the field, can be considerably changed. For example, if $L=r_{1}$, this shift is $\sqrt{2}$ times larger in comparison with the case of uniform magnetic field. From whence, a conclusion can be drawn that, in some cases, a nonuniform field gives rise to a better mass separation of particles.

We considered an axially symmetric magnetic field, in which the radial magnetic field component, $H_{r}$, is transverse with respect to the particle motion direction. The maximum value of this component is reached in the central part of the system at larger radii. In order to consider the capabilities of the particle mass separation in a reflected flux, we had to choose such conditions that the particles starting from a definite position shifted with respect to the axis should be reflected irrespective of the presence of the initial transverse velocity components.

The work of this system was simulated by two coils arranged so that the axis of the system passes through the centers of both coils. The magnetic field was created by transmitting the oppositely directed currents $J$ through the coils. The distributions of the magnetic field components $H_{z}$ and $H_{r}$ along the coordinates $z$ and $r$, respectively, were obtained from the azimuthal component $A_{\varphi}$ of the magnetic potential vector [7] for two symmetrically located rings written in cylindrical coordinates. With the help of the relations $H_{z}=\frac{1}{r} \frac{\partial}{\partial r}\left(r A_{\varphi}\right)$ and $H_{r}=-\frac{\partial A_{\varphi}}{\partial z}$, the magnetic field can be calculated in the cross-sections of the coils and in the volume between them using the formulas

$$
\begin{aligned}
& H_{z}=A\left\{\frac{E(k) \frac{a^{2}-r^{2}-(z+b)^{2}}{(a-r)^{2}+(z+b)^{2}}+K(k)}{\sqrt{(a+r)^{2}+(z+b)^{2}}}-\right. \\
& -\frac{\left.E\left(k_{1}\right) \frac{a^{2}-r^{2}-(z-b)^{2}}{(a-r)^{2}+(z-b)^{2}}+K\left(k_{1}\right)\right\}}{\left.\sqrt{(a+r)^{2}+(z-b)^{2}}\right\}}, \\
& H_{r}=A\left\{\frac{(z+b)\left[E(k) \frac{a^{2}+r^{2}+(z+b)^{2}}{(a-r)^{2}+(z+b)^{2}}-K(k)\right]}{r \sqrt{(a+r)^{2}+(z+b)^{2}}}-\right. \\
& \left.-\frac{(z-b)\left[E\left(k_{1}\right) \frac{a^{2}+r^{2}+(z-b)^{2}}{(a-r)^{2}+(z-b)^{2}}-K\left(k_{1}\right)\right]}{r \sqrt{(a+r)^{2}+(z-b)^{2}}}\right\},
\end{aligned}
$$

where $A=2 J /\left(c H_{0} L\right) ; E(k)$ and $K(k)$ are the complete elliptic integrals of the first and second kinds, respectively; their arguments are

$k=\left\{4 a r /\left[(a+r)^{2}+(z+b)^{2}\right]\right\}^{1 / 2}$,

ISSN 2071-0194. Ukr. J. Phys. 2015. Vol. 60, No. 12 
$k_{1}=\left\{4 a r /\left[(a+r)^{2}+(z-b)^{2}\right]\right\}^{1 / 2}$,

and $a$ is the coil radius. The system of equations for the motion of a charged particle in those fields looks like

$\ddot{r}-r \dot{\varphi}^{2}=\frac{e}{M c} r \dot{\varphi} H_{z}$,

$\frac{1}{r} \frac{d}{d t}\left(r^{2} \dot{\varphi}\right)=\frac{e}{M c}\left(\dot{r} H_{z}-\dot{z} H_{r}\right)$,

$\ddot{z}=-\frac{e}{M c} r \dot{\varphi} H_{r}$,

and the corresponding initial conditions are $t=0$, $r=r_{0}, z_{0}=-1, v_{r}=\dot{r}_{0}$, and $v_{z}=v_{0}$. The equations obtained were reduced to a dimensionless form. The following quantities were chosen to be the problem parameters: the magnetic field at the coil center $H_{0}$, half the distance between the coils $L$, and the longitudinal component of the velocity of a particle at the initial moment $v_{0}$. The motion of a particle was determined by the dimensionless parameter $p_{t}=M c v_{0} /\left(e L H_{0}\right)$.

The preliminary calculations were carried out for a magnetic field approximated in the near-axis region by the formulas $H_{z} \sim \sin \left(\frac{2 \pi}{L} z\right)$ and $H_{r} \sim$ $\sim \frac{\pi}{2 L} r \cos \left(\frac{2 \pi}{L} z\right)$. This allows us to estimate the range of parameters, at which the particles are totally reflected irrespective of whether they had initial transverse velocity components or not. Some results of those calculations are depicted in Fig. 1. One can see that the trajectory projections for two particles with different masses, which started from the same radius, considerably differ after the reflection. Particles with the identical masses but different directions of initial radial velocity have the minimal spread near a certain radius, with this radius being different for different masses. After the reflection, the particles become considerably shifted toward larger radii; in this case, we have to assume that the magnetic field at larger radii does not differ strongly from the field in the near-axis region.

To exclude the uncertainty associated with magnetic field values at large radii, further calculations were carried out for a field created by two coils. In this case, calculations are possible in the interval of parameter variations $k, k_{1} \leq 1$, which allows the fields to be calculated over the whole cross-sections of the coils and in the space between them. The distribution of the $H_{z}$ component of the magnetic field is depicted in Fig. 2 in relative units.

ISSN 2071-0194. Ukr. J. Phys. 2015. Vol. 60, No. 12

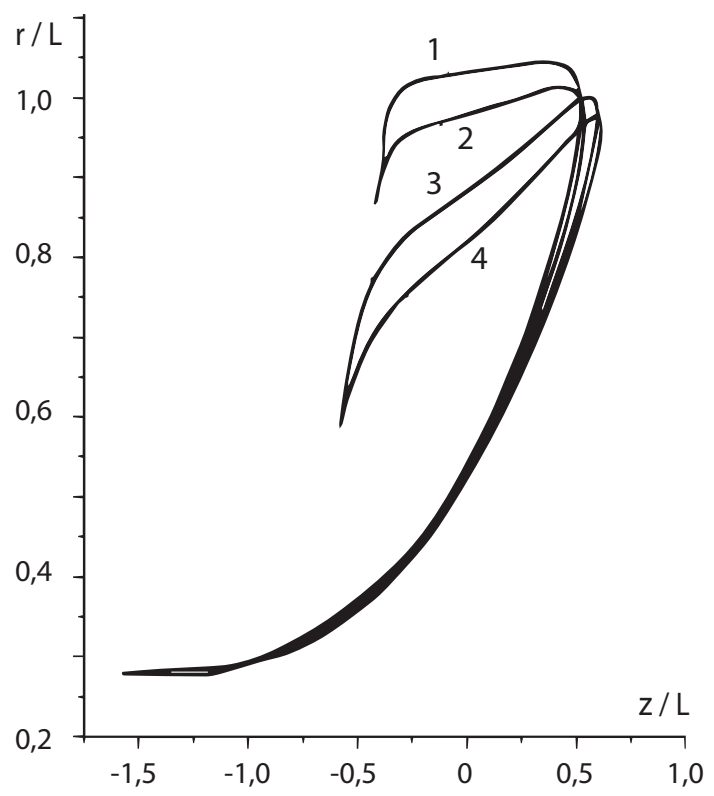

Fig. 1. Trajectory projections in the plane $(r, z)$ for two particles with close masses $\left(M_{1}<M_{2}\right)$, which start from the same radius. $M_{1}: v_{r} / v_{0}=3 \times 10^{-2}(1)$ and $-3 \times 10^{-2}$ (2); $M_{2}$ : $v_{r} / v_{0}=3 \times 10^{-2}(3)$ and $-3 \times 10^{-2}(4)$

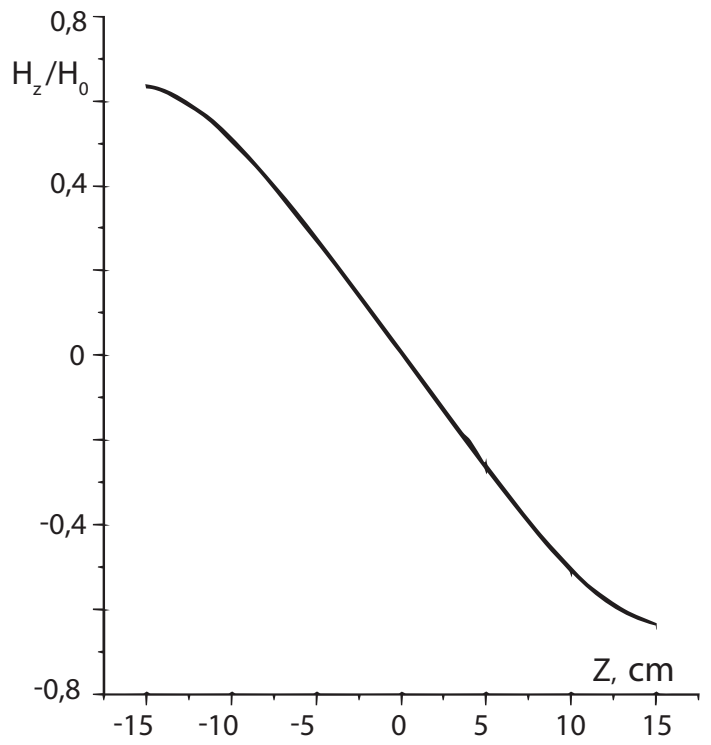

Fig. 2. Distribution of the $H_{z}$ component of a magnetic field at $r / L=0.25$

It was also supposed that the current in each coil could be varied independently. The allowable initial radial velocities, which provided a high separation coefficient, turned out to be of the same magnitude as 


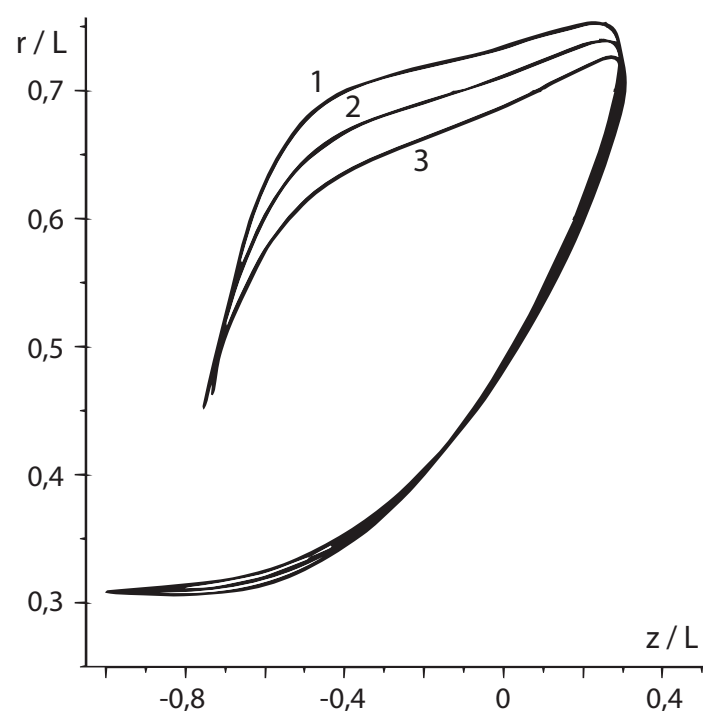

Fig. 3. Trajectory projections for particles with identical masses that start from the same position in the radial gap with various radial velocities $v_{r} / v_{0}=-0.02(1), 0$ (2), and 0.02 (3)

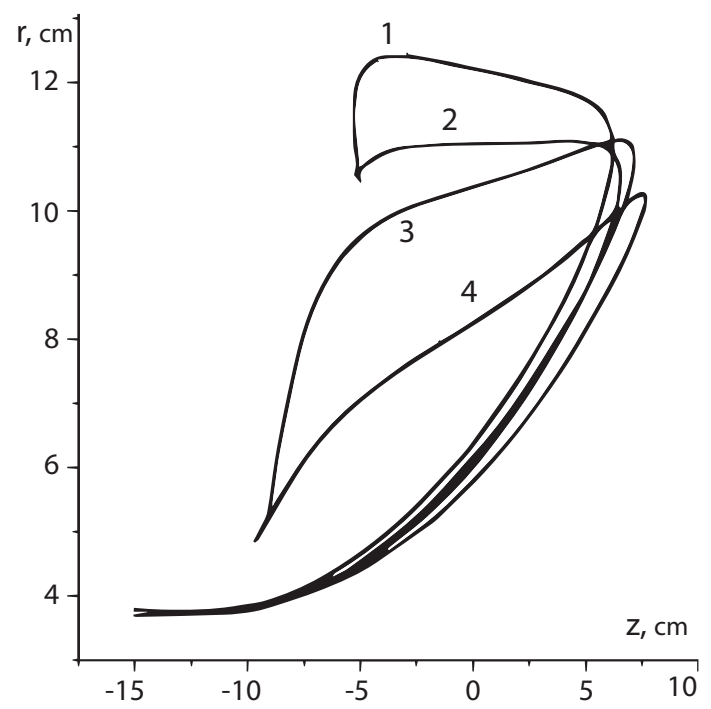

Fig. 4. Trajectory projections in the plane $(r, z)$ for particles with different masses in the magnetic field of two coils. The field distribution is described by formulas (1) and (2). The parameter $p_{t}=0.19$ (curves 1 and 2) and 0.21 (curves 3 and 4)

for the transmitting flux, i.e. $(3 \div 5) \times 10^{-2}$. Figure 3 illustrates some trajectory projections for particles with identical masses that start from the same radius, but with different initial radial velocities. One can see that, as was in the previous case, the trajectories of reflected particles are so distorted by the increasing magnetic field of the first coil that they grouped near a certain radius.

The radial size of the annular gap also affects the separation coefficient, so that its value should be selected so that the trajectories of particles with different masses would not intersect with one another. In Fig. 4, the projections of trajectories are shown for particles with close masses, which started from the lower and upper gap edges $(L=15 \mathrm{~cm})$. The particle mass is characterized by the parameter $p_{t}$. It is evident that the different start positions also give rise to a broadening of the particle motion region. As the particles move further, the increasing magnetic field of the first coil promotes particles with identical masses to group more compactly in a certain interval of radii, which is different for different masses. Particle collectors are reasonable to be mounted just at such radii.

Our calculations showed that isotopes in the reflected flux can be separated with a rather high coefficient, and a possibility of the separation along the radial coordinate allows the application of annular ionic sources. Our estimations evaluated the radial size of the annular gap to equal $0.1-0.15 \mathrm{~cm}$ for the parameters used in calculations. If the start radius equals $4 \mathrm{~cm}$, the ion-injecting area amounts to about $3 \mathrm{~cm}^{2}$. This allows the total current to be considerably increased and, accordingly, the performance of the system to be substantially enhanced in comparison with point-like sources. Moreover, there is no necessity in additional coils. The ion-injecting area in point-like sources is smaller than $1 \mathrm{~cm}^{2}$ even under optimal conditions. As an example, here are some separation parameters for a mixture of ${ }^{6} \mathrm{Li}$ and ${ }^{7} \mathrm{Li}$ ions, whose mass difference is close to the dimensionless parameters given in Fig. 4. At an energy of longitudinal ion motion of $50 \mathrm{eV}$, the separation along the radius amounts to $5 \mathrm{~cm}$ at the magnetic field $H_{0}=850$ Oe.

Hence, it is shown that the axially symmetric magnetic system with cusp field and the reflected flux can provide the mass separation of particles along the radius. It is found that the increasing magnetic field promotes the accumulation of separated isotopes with different masses at different radii. A capability of using an annular ion source allows the total current of injected isotope mixture to be increased, which enhances the performance of the system. In addition, in 
comparison with other variants of this configuration aimed at the separation of isotopes in the magnetic field, the system concerned is simpler, and its longitudinal size is shorter.

1. B.S. Akshanov and N.A. Khizhnyak, Pis'ma Zh. Tekhn. Fiz. 17, No. 6, 13 (1991).

2. B.S. Akshanov, V.F. Zelenskii, and N.A. Khizhnyak, Vopr. At. Nauki Tekhn. No. 4, 198 (2000).

3. A.G. Belikov and V.G. Papkovich, Vopr. At. Nauki Tekhn. No. 4, 58 (2004).

4. L.A. Bondarenko, A.G. Lymar, V.G. Papkovich, and V.A. Popov, Vopr. At. Nauki Tekhn. No. 4, 308 (2008).

5. K.D. Sinelnikov, N.A. Khizhnyak, N.S. Repalov et al., Plasma Physics and the Problem of Controlled Synthesis Reaction (Naukova Dumka, Kiev, 1965) (in Russian).

6. A.G. Belikov, V.P. Goncharenko, and N.A. Khizhnyak, Preprint KhFTI 85-24 (TsNIIatominform, Moscow, 1985) (in Russian).
7. A.I. Morozov and L.S. Solovyov, Vopr. Teor. Plazmy 2, 3 (1963).

Received 18.03.15.

Translated from Ukrainian by O.I. Voitenko

А.Г. Беліков, В.Г. Папкович

РОЗДІЛЕННЯ ІЗОТОПІВ У СИСТЕМІ

ІЗ ЗУСТРІЧНИМИ МАГНІТНИМИ ПОЛЯМИ У ВІДБИТОМУ ПОТОЦІ

$\mathrm{P}$ е $з$ ю м е

Розглянуто розділення ізотопів у відбитому пучку, який інжектувався в систему із зустрічними магнітними полями. Конфігурація магнітного поля створювалася двома кільцями 3 протилежно спрямованими струмами. Чисельно розраховувався рух частинок, які стартують зі входу системи, і потім відбиваються наростаючим магнітним полем другого кільця. Показана можливість розділення частинок по масах у радіальному напрямку після відбиття. Це дозволяє використовувати кільцеве джерело іонів, що приводить до збільшення повного струму, тобто до збільшення продуктивності системи. 